Document downloaded from:

http://hdl.handle.net/10251/143130

This paper must be cited as:

Polo, L.; Gómez-Cerezo, N.; García-Fernández, A.; Aznar, E.; Vivancos, J.; Arcos, D.; Vallet, M.... (12-2). Mesoporous Bioactive Glasses Equipped with Stimuli-Responsive Molecular Gates for Controlled Delivery of Levofloxacin against Bacteria. Chemistry - A European Journal. 24(71):18944-18951. https://doi.org/10.1002/chem.201803301

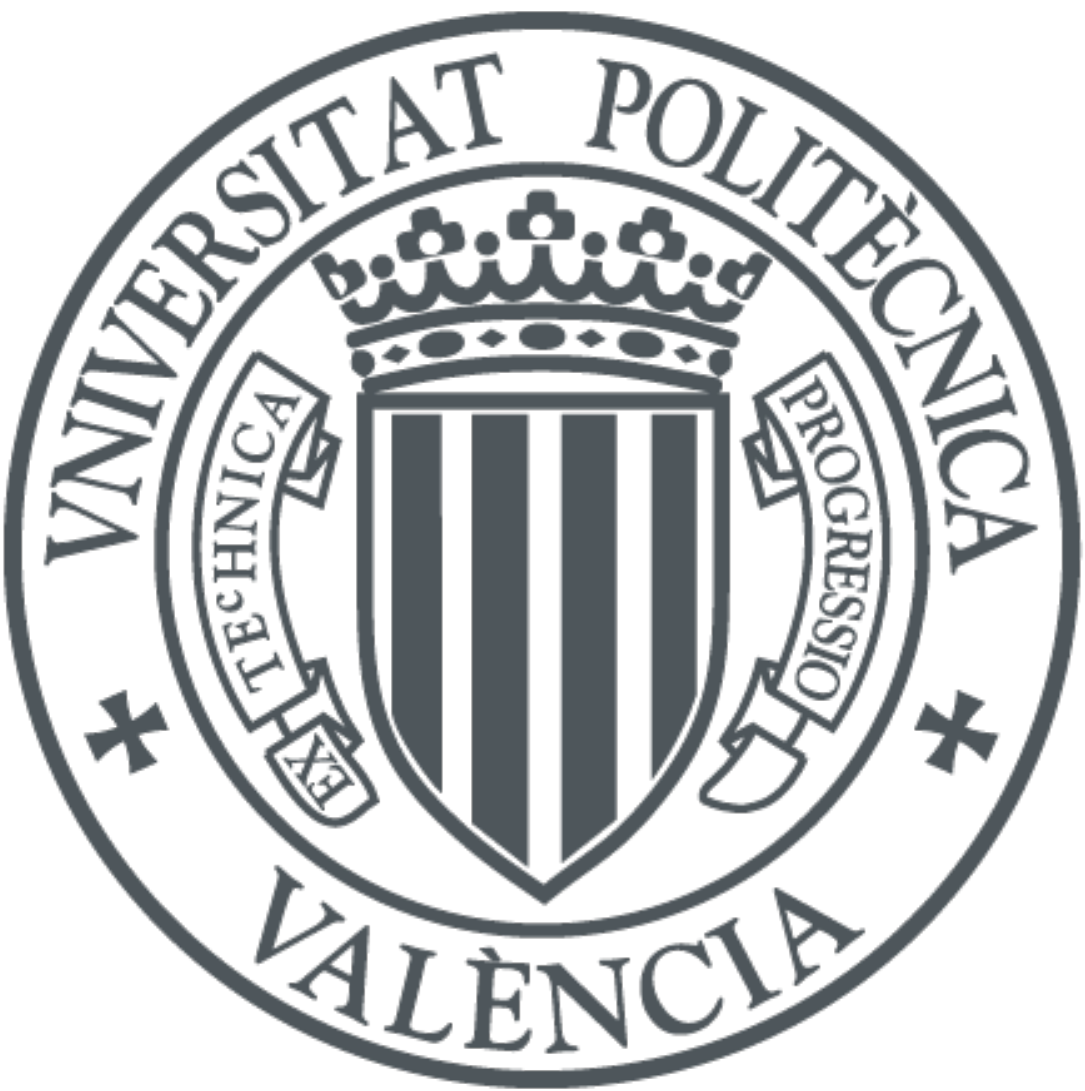

The final publication is available at

https://doi.org/10.1002/chem.201803301

Copyright John Wiley \& Sons

Additional Information 


\title{
Mesoporous bioactive glasses equipped with stimuli-responsive molecular gates for the controlled delivery of levofloxacin against bacteria
}

\author{
Lorena Polo, ${ }^{[a, b]}$ Natividad Gómez-Cerezo, ${ }^{[c, b]}$ Alba García-Fernández, ${ }^{[a, c, d]}$ Elena Aznar, ${ }^{[a, b, d]}$ José-Luis \\ Vivancos, ${ }^{[a, b, d, e]}$ Daniel Arcos, ${ }^{[c, b]}$ María Vallet-Regí, ${ }^{[c, b]}$ and Ramón Martínez-Máñez ${ }^{\star[a, b, d, e]}$
}

\begin{abstract}
Increase of bone diseases incidence has boosted the study of ceramic biomaterials as a potential osteo-inductive scaffolds. Particularly, mesoporous bioactive glasses have demonstrated to possess a broad application in the bone regeneration field, due their osteo-regenerative capability and their ability to release drugs from its mesoporous structure. These special features have been studied as an option to fight against bone infection, which is one of the most common problems regarding bone regeneration therapies. In this work, we develop a mesoporous bioglass functionalized with polyamines and capped with ATP as molecular gate for the controlled release of the antibiotic levofloxacin. Phosphate bonds of the ATP are hydrolyzed in the presence of acid phosphatase (APase), which significantly increases its concentration in bone infection due to the activation of bone resorption processes. The solid has been characterized and tested successfully against bacteria. The final gated solid only induces bacterial death in the presence of acid phosphatase. Additionally, it has also been demonstrated that the solid is not toxic for human cells. The double
\end{abstract}

[a] L. Polo, A. García-Fernández, Dr. E. Aznar, Dr. J.L. Vivancos, Prof. R. Martínez-Máñez

Instituto Interuniversitario de Investigación de Reconocimiento Molecular y Desarrollo Tecnológico (IDM), Universitat Politècnica de València, Universitat de València

Camino de Vera s/n, 46022, Valencia, Spain.

E-mail: rmaez@qim.upv.es

[b] L. Polo, N. Gómez-Cerezo, A. García-Fernández, Dr. E. Aznar, Dr. J.L. Vivancos, Dr. D. Arcos, Prof. M. Vallet-Regí, Prof. R. MartínezMáñez.

CIBER de Bioingeniería Biomateriales y Nanomedicina (CIBERBBN), Spain.

[c] N. Gómez-Cerezo, Dr. D. Arcos, Prof. M. Vallet-Regí. Departamento de Química en Ciencias Farmacéuticas (Química Inorgánica y Bioinorgánica)

Facultad de Farmacia

Universidad Complutense de Madrid, Plaza Ramón y Cajal s/n 28040, Madrid, Spain

[d] A. García-Fernández, Dr. E. Aznar, Dr. J.L. Vivancos, Prof. R. Martínez-Máñez.

Unidad Mixta UPV-CIPF de Investigación en Mecanismos de Enfermedades y Nanomedicina, Universitat Politècnica de València, Centro de Investigación Príncipe Felipe, Valencia, Spain.

[e] Dr. J.L. Vivancos, Prof. R. Martínez-Máñez.

Unidad Mixta de Investigación en Nanomedicina y Sensores. Universitat Politècnica de València, Instituto de Investigación Sanitaria La Fe, Valencia, Spain

Supporting information for this article is given via a link at the end of the document. function of the prepared nanodevice as drug delivery system and bone regeneration enhancer, confirms the possible development of a new approach in tissue engineering field, where controlled release of therapeutic agents can be finely tuned at the same time that osteoinduction is favoured.

\section{Introduction}

Bone diseases have gained importance over the last years due to the ageing of population. Incidence of illnesses like osteoporosis, bone tumours and bone fractures is remarkably higher in elderly patients, due to age-related loss and weakening of bone tissue. ${ }^{[1]}$ Treatment of these kind of diseases usually implies the use of implants and bone prosthesis; however, surgical procedures are not always infallible, since they can result in other medical complications..$^{[2,3]}$ Currently, bacterial infection is one of the most frequent problems related to implant surgery. ${ }^{[4]}$ The creation of a bacterial biofilms on the surface of the implant requires many times its removal and leads to healing difficulties, lowering the life-quality of patients. ${ }^{[5]}$ Therefore, the need of new therapies and devices for the treatment of these diseases has led to arise the development of innovative biomaterials for bone tissue engineering. ${ }^{[6,7]}$ Among them, mesoporous bioactive glasses are promising and innovative silica-based bioceramics which have a meaningful significance in bone tissue engineering field due to their excellent properties. ${ }^{[8-10]}$ These materials are biocompatible and resorbable, and are able to integrate living bone in a physiological environment through the formation of hydroxyapatite on the surface of the implant. ${ }^{[11,12]}$ This apatite-like phase is very similar to the inorganic component of the bones, and its enhanced formation in bone defects greatly favours bone regeneration. ${ }^{[13]}$ These features make mesoporous bioactive glasses ideal materials for bone grafting and bone regeneration therapies. Apart from that, their mesoporous structure gives them special surface features, ${ }^{[14]}$ and converts them suitable for drug delivery of certain substances. ${ }^{[15,16]}$

Several studies have reported the storage and release of different therapeutic drugs in order to treat local bone pathologies. ${ }^{[17]}$ However, these examples are in most cases 
based on sustained release processes which are not able to avoid unspecific release. Taking into account these precedents, it is of interest the development of more sophisticated systems able to promote bone regeneration and achieve controlled drug delivery only in specific scenarios. Various nanostructured systems have been recently designed for the controlled release of anticancer and antiviral drugs. ${ }^{[18,19]}$ Moreover, the preparation of new drug nanocarriers able to respond to external stimuli to perform a controlled and local cargo release has been of enormous importance in the field of biomedicine. ${ }^{[20,21]}$ In this context, one appealing approach to succeed in this goal is the incorporation of molecular gates to mesoporous bioglasses. A molecular gate is a molecular or supramolecular-based system able to control mass transport and respond to specific external stimuli which can be implemented in a porous scaffold. ${ }^{[22,23]}$ Different gated materials using molecules, biomolecules or supramolecules have been described. In these examples, the gating mechanism can be switched between a "closed" to "open" state, or vice versa, by the application of a selected stimulus as light, ${ }^{[24]}$ temperature, ${ }^{[25,26]}$ magnetic fields, ${ }^{[27]}$ ultrasounds, ${ }^{[28]} \mathrm{pH}$ changes, ${ }^{[29]}$ redox reactions ${ }^{[30]}$ or biomolecules as enzymes. ${ }^{[31-24]}$ Molecular gates have been widely studied and incorporated in mesoporous silica supports, ${ }^{[35]}$ but very rarely have been implemented in mesoporous bioglasses. ${ }^{[36]}$ Despite the relevance of combining the osteoinductive features of mesoporous bioactive glasses and controlled release characteristics of molecular gates, much effort in the development of this kind of functional biomaterials should still be accomplished and applied to a relevant context. In this scenario, the aim of this work is the development of a gated system able to respond specifically to the presence of a stimulus related with bone infection.

For this purpose, an $80 \% \mathrm{SiO}_{2}-15 \% \mathrm{CaO}-5 \% \mathrm{P}_{2} \mathrm{O}_{5}(\% \mathrm{~mol})$ mesoporous bioglass was selected as inorganic support (S1). This solid was loaded with levofloxacin, which is a wide range antibiotic, and functionalized with 3-[2-(2aminoethylamino)ethylamino]propyl-trimethoxysilane. The resulting solid (S2) was treated with ATP (Adenosine 5'triphosphate disodium salt hydrate) and EDC, in order to covalently attach the phosphate group in ATP with the amine in N3 (solid S3). In this way, ATP molecules were grafted to the surface of the solid, blocking the entrance to the mesopores and keeping the cargo in the pore voids. In a non-pathological scenario, ATP molecules would remain intact, and levofloxacin would continue stored inside the pores of the mesoporous bioactive glasses. However, in the presence of a stimulus as acid phosphatase (APase), ATP molecules would be hydrolysed, unblocking the surface of the pores and allowing the release of the drug. This mechanism has been previously used by the present authors to develop gated 3D scaffolds and as intracellular drug delivery system. ${ }^{[37,35]}$ APase was selected as stimulus since its concentration significantly increases with osteoclast activity. ${ }^{[38,39]}$ Both osteoblast deposition and osteoclast resorption are two balanced processes which are fundamental for bone regeneration. ${ }^{[40]}$ However, the presence of infectious microorganisms as Staphylococcus aureus can enhance osteoclast resorption and lead into bone damage with the subsequent increase of acid phosphatase levels. ${ }^{[41]}$ The action mechanism of phosphatase enzymes consists of the cleavage of phosphate bonds. Thus, in a bone infection scenario ATP molecules would be cleaved, unblocking the entrance to the mesopores of the MBG and allowing the release of the drug

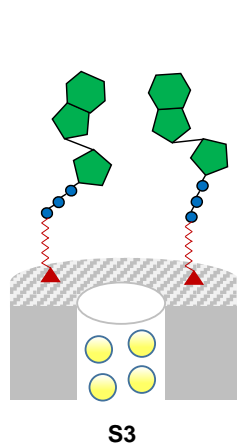

S3

CLOSED GATE

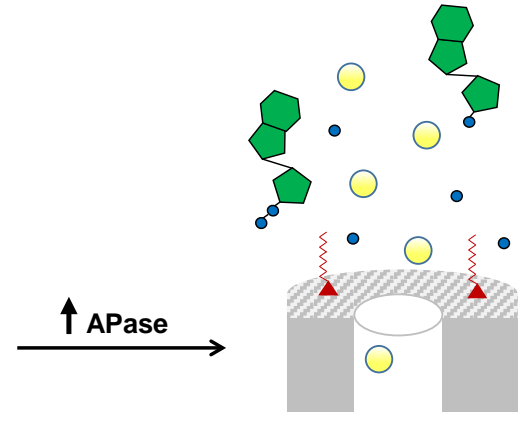

S3

OPEN GATE

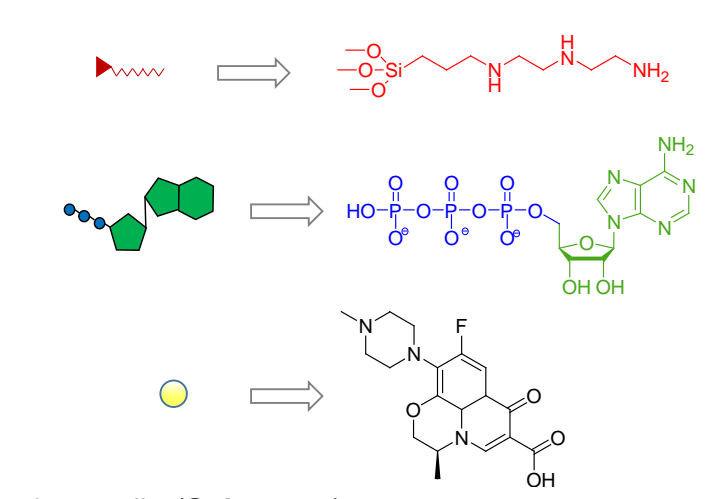

to the media (Scheme 1).

Scheme 1. Schematic representation of solid S3 capped with the ATP molecular gates.

The resulting solid (S3) was characterized, to assure that the functionalization process did not modify the properties of the support. Controlled release tests were carried out both in the presence and the absence of acid phosphatase achieving drug release only in the presence of the stimulus. Bioactivity assays were carried out with gated and nongated solids, to demonstrate that the molecular gates do not slow down bioactive processes. Moreover, bacterial death experiments were carried out in order to confirm the antibacterial activity of the solid in a specific scenario. Finally, cytotoxicity assays were carried out with the gated solid to assess that the solid is not toxic for human cells.

\section{Results and Discussion}


The aim of this work was the development of a gated bioglas able to deliver an antibiotic (levofloxacin) in the presence of a stimulus (presence of APase) related with bone infection. For this, a mesoporous bioactive glass (solid S1) was loaded with levofloxacin and then functionalized first with N3 and then with ATP to yield solids S2 and S3, respectively. The synthesized solids were correspondingly characterized in order to confirm the presence of the ATP gates, and to demonstrate that the mesoporous properties of the final solid S3 had not been damaged upon the functionalization and capping processes. Thus, chemical, structural and textural characterization was carried out in solids S1, S2 and S3. The highly ordered mesoporous structure of the solids was confirmed by powder X-ray diffraction (XRD). XRD pattern for S1 (Figure 1) shows a single peak at $1.71^{\circ}$ that corresponds to a (10) Bragg reflection of a 2D hexagonal p6m structure. S2 and S3 show similar peaks. Peaks intensity decreases after the loading and capping process, pointing out the introduction of certain degree of disorder with these processes.

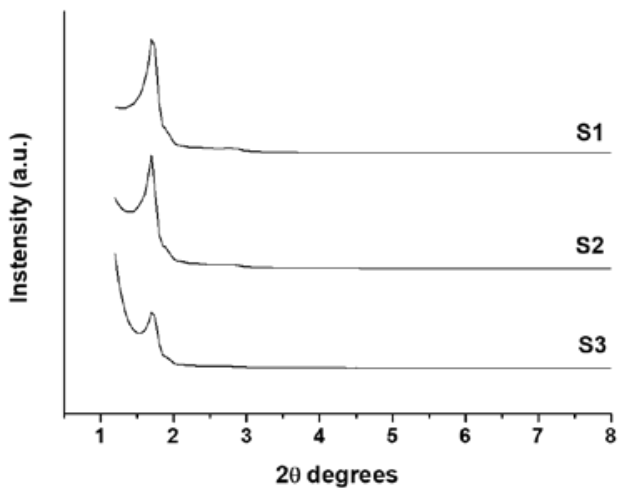

Figure 1. Powder X-ray diffraction patterns of solids S1, S2 and S3.

Transmission electron microscopy studies were also carried out in order to confirm XRD results. TEM image of S1 evidences mesoporous structure, showing alternate black and white stripes typical of $\mathrm{p} 6 \mathrm{~m}$ hexagonal pore symmetry (Figure 2). TEM images of $\mathbf{S 2}$ and $\mathbf{S 3}$ show that mesoporous structure of the solids was not affected during the loading, functionalization and capping processes.

Textural properties of the prepared materials were characterized by $\mathrm{N}_{2}$ adsorption-desorption studies. The $\mathrm{N}_{2}$ adsorption-desorption isotherm of $\mathbf{S} 1$ shows a curve of type IV, typical of mesoporous solids (Figure 3). The curve shows an adsorption step between $\mathrm{P}^{\mathrm{P}} \mathrm{P}_{0} 0.4$ and 0.6 , due to $\mathrm{N}_{2}$ condensation inside pores. Moreover, the curve has a $\mathrm{H} 1$ hysteresis loop also typical of mesoporous materials, which indicates that mesopores have open cylinder morphology. $\mathrm{N}_{2}$ adsorption-desorption isotherm of S3 shows a decrease of BET surface and specific pore volume when compared with $\mathbf{S 1}$, due to the loading of the pores

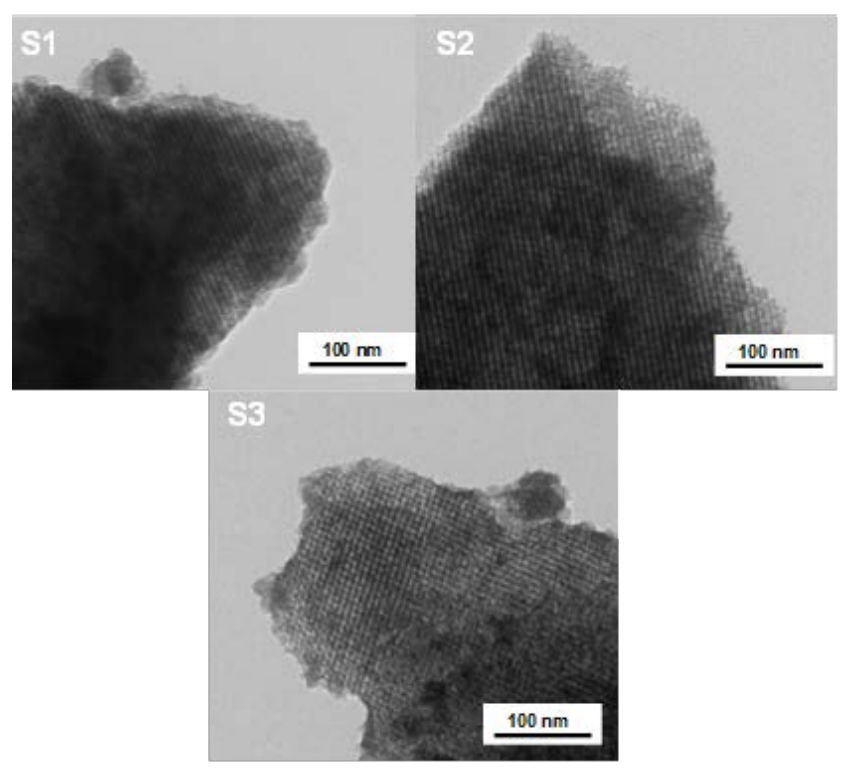

Figure 2. Transmission electron microscope images of solids $\mathbf{S 1}, \mathbf{S 2}$ and S3.

and grafting of ATP. The hysteresis loop of the curve for S3 changes to type $\mathrm{H} 2$ when compared with that of $\mathbf{S 1}$, which means that the morphology of the pore has also changed, indicating an ink-bottle shape according to the capping of the material. Finally, pore size distribution was determined from the adsorption branch of the isotherm by means of the Barret-Joyner-Halenda $(\mathrm{BJH})$ method and the surface area was determined using the Brunauer-Emmett-Teller (BET) method. Textural parameters values of S1 and S3 are summarized in Table 1.

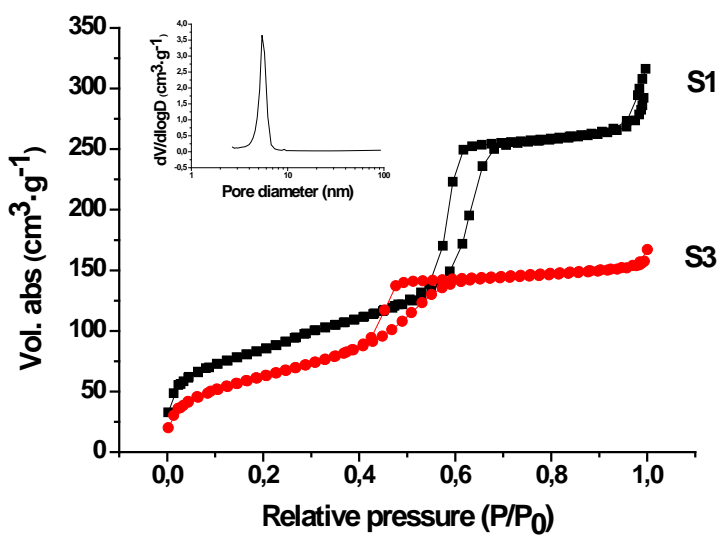

Figure 3. $\mathrm{N}_{2}$ adsorption-desorption isotherms for solids $\mathbf{S 1}$ and $\mathbf{S 3}$.

Moreover, thermogravimetric analysis was performed in solid S3 to determine the amount of N3 and ATP attached to the surface of the material. Results are shown in Table 2. Moreover, the amount of levofloxacin contained into the pores was determined. For this, $10 \mathrm{mg}$ of solid S3 were treated with APase and the solid allowed to release the 
cargo for 24 hours. From a fluorescence calibration curve, it was determined that the amount of levofloxacin was 2.53 mg per gram of $\mathbf{S} 3$.

Table 1. Textural parameters of solids S1 and S3.

\begin{tabular}{cccc}
\hline Solid & $\begin{array}{c}\text { BET surface } \\
\left(\mathbf{m}^{\mathbf{2}} \cdot \mathbf{g}^{-1}\right)\end{array}$ & $\begin{array}{c}\text { Pore Volume } \\
\left(\mathbf{c m}^{\mathbf{3}} \mathbf{~ g}^{-1}\right)\end{array}$ & Pore size $(\mathbf{n m})$ \\
\hline S1 & 305.50 & 0.386 & 5.5 \\
S3 & 233.98 & 0.210 & 3.9 \\
\hline
\end{tabular}

Table 2. Organic content ( $\alpha, \mathrm{mg} / \mathrm{g}$ of solid) in solid S3.

\begin{tabular}{llll}
\hline Solid & $\boldsymbol{\alpha}_{\text {levo }}$ & $\boldsymbol{\alpha}_{\mathrm{N} 3}$ & $\boldsymbol{\alpha}_{\text {ATP }}$ \\
\hline S3 & 2.53 & 179.8 & 22.97 \\
\hline
\end{tabular}

As previously stated, the designed nanodevice is based on the combination of a biocompatible material and a gating mechanism to induce apatite-like formation and control drug release at the same time. For this reason, both bioactivity and drug delivery assays were carried out with solid S3. In order to demonstrate that the ATP-capped solid is capable to release the payload only in specific scenarios, drug delivery studies were undertaken in the presence and the absence of acid phosphatase. In a typical experiment, $2 \mathrm{mg}$ of S3 were suspended in water at $\mathrm{pH} 7.6$ and stirred for 24 hours in the presence and the absence of the stimulus. At given time intervals, fractions of both suspensions were taken and filtrated to remove the solid. Then, drug released from the pore voids was monitored by fluorescence spectroscopy ( $\lambda_{\mathrm{ex}} 292 \mathrm{~nm}, \lambda_{\mathrm{em}} 494 \mathrm{~nm}$ ). Drug delivery kinetics is shown in Figure 4. In the absence of stimulus, the solid showed poor release, (less than $20 \%$ of the maximum cargo delivered). Contrarily, in the presence of acid phosphatase, a remarkable payload of the drug was achieved, reaching maximum delivery at 24 hours. These results are consistent with the design of the nanodevice. In the absence of APase, the ATP gates remain closed, blocking the entrance to the pores and avoiding levofloxacin leakage. When acid phosphatase is added the phosphate bonds in ATP are hydrolysed, pore entrances are unblocked and levofloxacin is released.

In order to demonstrate that gate opening was caused by the presence of APase, controlled release experiments were carried out in the presence of other enzymes as amylase and lipase. Delivery kinetics of this experiment are shown in Figure $\mathbf{4}$ and demonstrate that the presence of other enzymes did not induce cargo delivery.

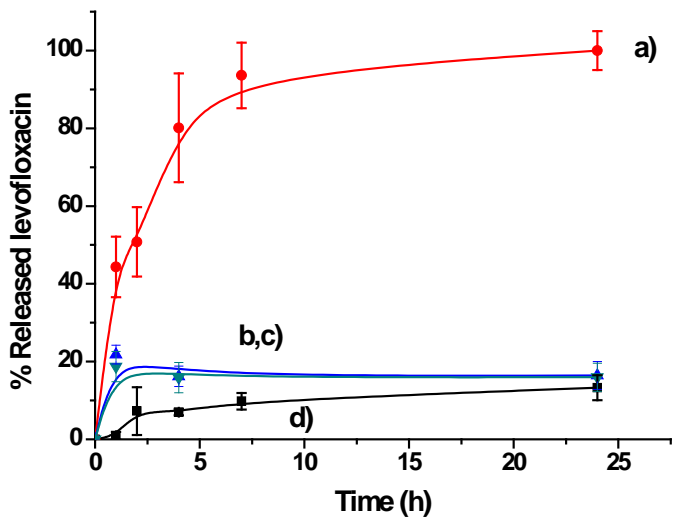

Figure 4. Delivery kinetics of solid $\mathbf{S} 3$ in the presence of acid phosphatase (a), amylase (b) and lipase (c), and in the absence of acid phosphatase (d).

Additionally, levofloxacin kinetics release can be explained by using the Higuchi model. ${ }^{[42,43]}$ This simple model, used for similar systems, ${ }^{[44]}$ predicts that the release of the cargo will be dependent on the square root of time when delivery is based on a Fickian diffusion process. In this case, the amount of guest release, Qt, per unit of exposed area at time t can be described by the equation:

$Q_{t}=k_{H} t^{1 / 2}$

where $\mathrm{k}_{\mathrm{H}}$ is the release rate constant for the Higuchi model. When applied to the experimental data, a good linear fitting was observed (see Figure 5) and a value of $\mathrm{K}_{\mathrm{H}}$ of 35,836 was calculated. These data suggest that the delivery of levofloxacin from pores of solid $\mathbf{S 3}$ is basically a diffusive process.

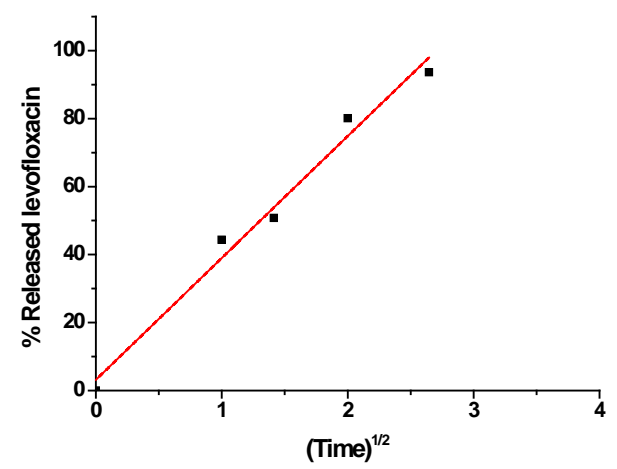

Figure 5. Delivery kinetics of solid S3 versus the square root of time

Molecular gates provide to mesoporous bioactive glass the ability to perform controlled drug release, but also imply a certain modification of the bioactive glass surface. Therefore, we found important to check that the molecular gates did not harm the bioactive capability of the material. Thus, the bioactive behaviour of solid S3 was studied by soaking the material in simulated body fluid (SBF) at $37^{\circ} \mathrm{C}$. As solid $\mathbf{S 3}$ was meant to be bioactive in the presence of 
acid phosphatase, the bioactivity test with $\mathbf{S} 3$ was carried on in the absence and the presence of the enzyme in order to study the system with both, open and closed gates. Bioactivity of solids was studied by FTIR spectroscopy to identify the signals corresponding to the presence of phosphate bonds. In addition, field emission scanning microscopy images were taken with the purpose of confirming FTIR results, and EDX analysis was performed in order to study the components of the solids surface before and after soaking in SBF. FTIR spectra of S3 in the presence and the absence of APase at 0 and 72 hours are shown in Figure 6. Non-soaked solid $\mathbf{S 3}$ shows typical Si-O signal at $900-1250 \mathrm{~cm}^{-1}$, and signal in 520-610 $\mathrm{cm}^{-1}$ corresponding to the presence of amorphous phosphate bonds. Moreover, amine $\delta(\mathrm{C}-\mathrm{N})$ and $\delta(\mathrm{C}-\mathrm{H})$ bands are observed at $1470 \mathrm{~cm}-1$ and $1650 \mathrm{~cm}-1$. A typical weak amine $\delta(\mathrm{N}-\mathrm{H})$ band is also observed at $3250 \mathrm{~cm}-1$. The FTIR spectrum of S3 after being soaked for 72 hours in the absence of APase remains unchanged. FTIR spectra of solid S3 in the presence of acid phosphatase shows typical MBG signals and amine signals at 1470, 1650 and 3300 $\mathrm{cm}^{-1}$, but a splitting of the signal at 560 and $600 \mathrm{~cm}^{-1}$ is also clearly observed after 24 and 72 hours of soaking. This splitting demonstrates the presence of $\mathrm{P}-\mathrm{O}$ bonds corresponding to a crystalline phase, which is consistent with the formation of apatite.

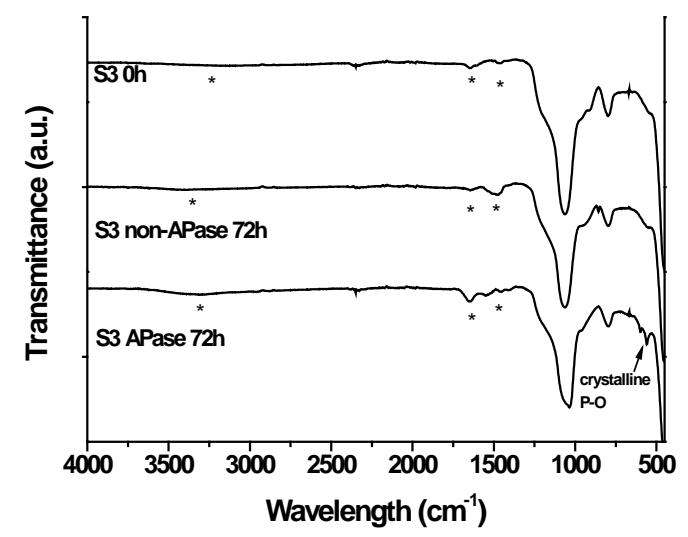

Figure 6. FTIR spectra of non-soaked S3, 72 hours soaked S3 with no APase, and 72 hours soaked $\mathbf{S} 3$ with APase.

In order to confirm the results given by FTIR spectroscopy, FESEM images of the different treated solids were taken, and EDX analysis was performed. $\mathrm{Si}, \mathrm{Ca}$ and $\mathrm{P}$ percentages are shown in Table 3. Non-soaked solid S3 showed a neat surface with no apatite (Figure 7A), and S3 soaked for 72 hours in the absence of APase also presents the same neat surface, with low calcium and phosphor percentages (Figure 7B). Actually, for the later the amount of calcium decreases due to the release of $\mathrm{Ca}^{2+}$ ions from the mesoporous bioglass. $\mathrm{Ca}^{2+}$ release from the material also causes the rise of silicon percentage, while phosphorous amount slightly rises too. These results are

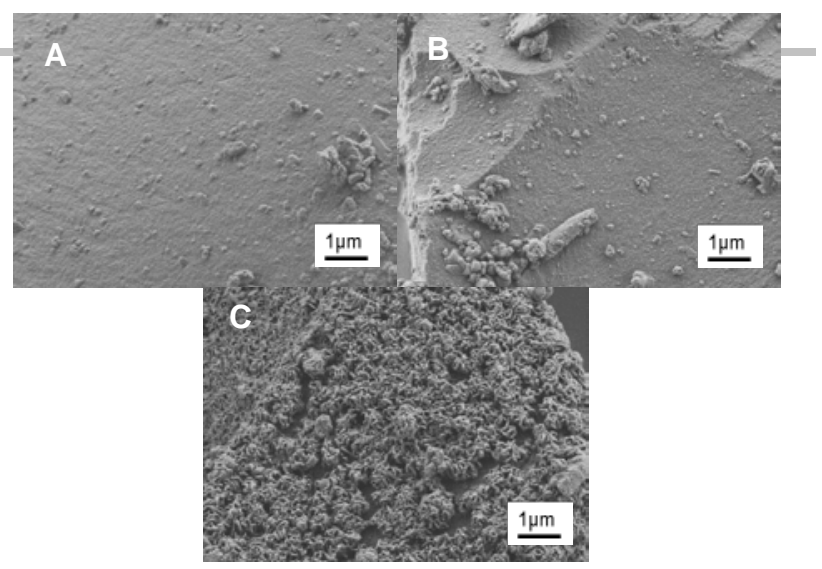

Figure 7. SEM images of non-soaked $\mathbf{S 3}(\mathrm{A}), 72$ hours soaked $\mathbf{S 3}$ with no APase (B), and 72 hours soaked $\mathbf{S 3}$ with APase (C).

consistent with FTIR spectra, which show no crystalline P-O presence in S3 containing the ATP molecular gates. However, when S3 is soaked for 72 hours in the presence of acid phosphatase, a new thick phase is rapidly formed on the surface of the solid (Figure 7C). EDX analysis confirms the high amounts of calcium and phosphorous. Ratio $\mathrm{Ca} / \mathrm{P}$ was found to be 1.46, which is in agreement with the presence of the apatite-like phase. These results are also consistent with FTIR spectra, demonstrating that the solid with "open gates" recovers its bioactive properties.

Table 3. EDX results of $\mathrm{Si}, \mathrm{Ca}$ and $\mathrm{P}$ percentages in non-soaked S3, 72 hours soaked S3 with no APase, and 72 hours soaked S3 with APase.

\begin{tabular}{llll} 
\% & S3 $\mathbf{~ h ~}$ & S3 72h & S3-APase $\mathbf{7 2 h}$ \\
\hline $\mathrm{Si}$ & 85.37 & 90.03 & 75.66 \\
$\mathrm{Ca}$ & 11.13 & 6.01 & 14.46 \\
$\mathrm{P}$ & 3.50 & 3.96 & 9.88 \\
\hline
\end{tabular}

The loss of bioactivity after the incorporation of the ATP molecular gates has not been deeply studied in this work. A hypothetical explanation to the non-bioactive behaviour of solid $\mathbf{S 3}$ in the absence of acid phosphatase could be related to the ability of mesoporous bioglasses to release $\mathrm{Ca}^{2+}$ ions to the media. As stated in literature, ${ }^{[45]}$ bioactive processes start with the $\mathrm{Ca}^{2+}$ leaking from the silica net and undergoing an exchange with $\mathrm{H}^{+}$ions. In a physiological media, calcium ions are capable of reacting with phosphates to form a crystalline apatite layer. It has also been reported that phosphate groups have a high affinity for $\mathrm{Ca}^{2+}$ ions. ${ }^{[45]}$ In this context, it is possible that the phosphate net formed by the ATP molecules could entrap $\mathrm{Ca}^{2+}$ ions, avoiding the leakage to the media and therefore inhibiting bioactive behaviour. Moreover, the breaking of the phosphate net would allow the entrapped calcium release, which is consistent with results of $\mathbf{S} 3$ in the presence of acid phosphatase. Actually, the release of ATP molecules would rise phosphates concentration in the media, which could also favour the apatite phase formation.

Thus, solid S3 was not bioactive when capped with ATP. However, once mimicked bacterial infection conditions (with 
the subsequent increase of acid phosphatase in the media), the $\mathbf{S} 3$ bioactivity was restored.

As solid S3 was expected to release an antibiotic drug in the presence of an infection, bacterial viability assays were carried out with the purpose of demonstrating the bactericide effect of the nanomaterial. In a typical experiment $\mathbf{S} 3$ was stirred at $37^{\circ} \mathrm{C}$ in the absence and the presence of acid phosphatase for 24 hours. Then, two different E.coli suspensions were treated with $50 \mu \mathrm{L}$ of each sample. Bacteria were stirred for 20 minutes and afterwards $100 \mu \mathrm{L}$ of each suspension was seeded in an agar plate and incubated at $37^{\circ} \mathrm{C}$. After 24 hours, cell viability was quantified by counting the colonies. As seen in Figure $\mathbf{8}$, bacteria treated with the $\mathbf{S 3}$ suspension (without APase) showed a viability of $80.41 \%$, which is remarkably higher than $18.75 \%$ of viability when bacteria were treated with the S3 suspension previously treated with APase. Decreased viability for the former compared with control $(100 \%)$ can be due to the residual release of levofloxacin in the absence of acid phosphatase. Moreover, bacteria were also treated with a solution containing only APase and no significant bacterial death was observed, demonstrating that the bacterial death was due to the presence of released levofloxacin (data not shown). These results are consistent with the design of the gated support S3. In the presence of acid phosphatase, the gated support delivers levofloxacin in a much higher amount that that in the absence of the stimulus. The higher concentration of drug in APase supernatant undertakes higher cell toxicity, demonstrating that the bactericide effect of the solid is only achievable in the presence of an infection marker as acid phosphatase.

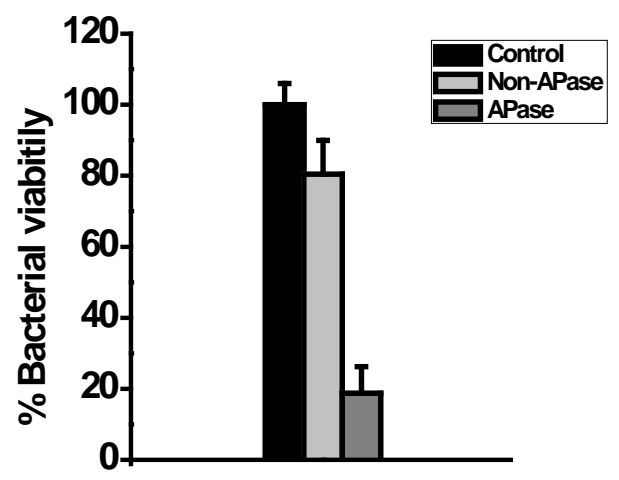

Figure 8. Bacterial viability of E.coli when treated with 50 and $100 \mu \mathrm{L}$ of a suspension of $\mathbf{S} \mathbf{3}$ in the presence and the absence of APase.

Finally, cytotoxicity studies were carried out in order to demonstrate that the prepared material is compatible with human cells. For this purpose, U-2 OS human osteosarcoma cells were treated with different amounts (25, 50,100 and $200 \mu \mathrm{g} \cdot \mathrm{mL}^{-1}$ ) of $\mathrm{S} 3$ for 24 and 48 hours, and mitochondrial activity (WST-1 assays) was measured after these intervals. As seen in Figure 9, S3 solid was well- tolerated by U-2 OS cells at concentrations up to 200 $\mu \mathrm{g} \cdot \mathrm{mL}^{-1}$ after 24 and 48 hours of exposure, which means that the prepared solid is not toxic. Thus, it was demonstrated that the ATP-gated mesoporous bioactive glass is biocompatible, and is a good strategy to treat bone infection and improve bone regeneration without causing any damage to human cells.

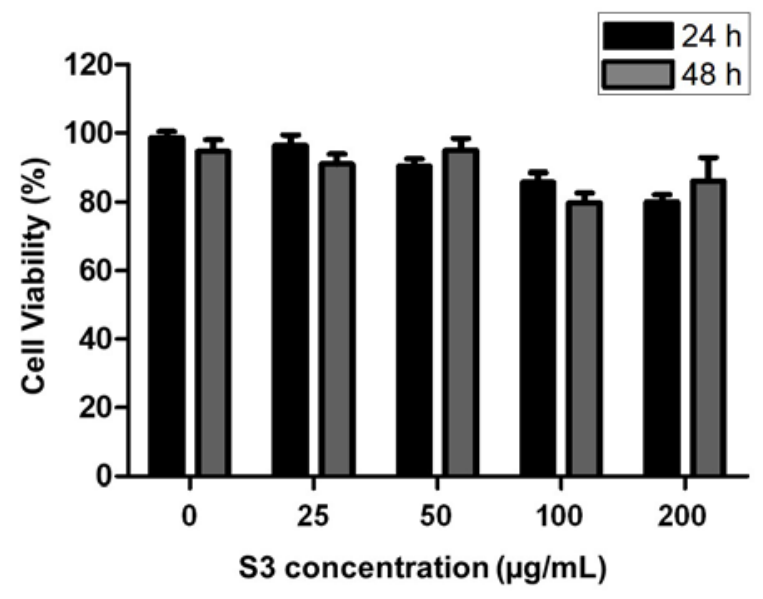

Figure 9. Cell viability of U-2 OS cells in the presence of $\mathbf{S} 3(0,25,50$, 100 and $200 \mu \mathrm{g} \cdot \mathrm{mL}^{-1}$ ) after 24 hours (black) and 48 hours (gray) of incubation. Three independent experiments containing triplicates were carried out. Data are expressed as mean \pm s.e.

\section{Conclusions}

In summary, we have developed a double-strategy device which is able to enhance bone regeneration and achieve controlled drug release against bacteria. A mesoporous bioactive glass was loaded with levofloxacin, functionalized with a polyamine, and capped with ATP molecules. The structure of the resulting solids was characterized by standard techniques, demonstrating that the incorporation of molecular gates into MBG did not imply any changes in its textural properties. Then, both drug release capability and bioactive behaviour were tested. Drug release experiments were carried out with the final solid in the presence and the absence of acid phosphatase, and also in the presence of other enzymes as amylase and lipase, observing only a complete release of the drug when acid phosphatase was present. This demonstrates that controlled release is achieved only in the presence of a specific stimulus typical of a bone infection environment. On the other hand, bioactivity studies were carried out with S3 in the presence and the absence of acid phosphatase. Our studies proved that the solid did not have bioactive capabilities when capped with ATP gates, however, it was found that the solid recovered its bioactive behaviour in the presence of the acid phosphatase stimulus. Antibacterial effect of S3 was also studied, and it was demonstrated that solid treated with acid phosphatase was much more effective killing bacteria than the untreated solid. Finally, 
cytotoxicity studies were carried out with $\mathbf{S 3}$, showing that the prepared material was not toxic for U-2 OS human cells upon 24 and 48 hours. In this way, our double-strategy design has been proved to be successful as a drug delivery system and bone regeneration enhancer. The present work confirms the versatility of the used gating mechanism previously applied to the development of 3D scaffolds and as intracellular drug delivery system. This kind of doubleedged nanodispositives opens up a new approach in tissue engineering field, particularly in the treatment of osseous diseases as bone infection.

\section{Experimental Section}

\section{Chemicals}

Chemicals poly(ethylene glycol)-block-poly(propylene glycol)-blockpoly(ethylene glycol) (P123), tetraethyl orthosilicate (TEOS), triethyl phosphate (TEP), calcium nitrate $\mathrm{Ca}\left(\mathrm{NO}_{3}\right) 2 \cdot 4 \mathrm{H}_{2} \mathrm{O}, \quad 3-[2-(2-$ aminoethylamino)ethylamino]propyl-trimethoxysilane (N3), adenosine 5'triphosphate disodium salt hydrate (ATP), N-(3-dimethylaminopropyl)-N'ethylcarbodiimide hydrochloride (EDC), acid phosphatase, acetonitrile anhydrous, hydrochloric acid, levofloxacin, Dulbecco's Modified Eagle's Medium (DMEM), fetal bovine serum (FBS) and Dulbecco's phosphatebuffered saline (PBS) were purchased from Sigma-Aldrich Química S.A. LB medium was provided from Laboratorios Conda. Cell proliferation reagent WST-1 was obtained from Roche Applied Science.

\section{General Techniques}

FTIR spectroscopy was carried out with a Tensor 27 FT-IR spectrometer (Bruker). TEM images were obtained with a $100 \mathrm{kV}$ Jeol JEM-1010 microscope. FESEM images were obtained with a ZEISS ULTRA 55. Powder X-ray diffraction measurements were performed on a Philips D8 Advance diffractometer using $\mathrm{Cu}$ Ka radiation. Textural properties of the calcined materials were determined by nitrogen adsorption porosimetry by using a Micromeritics TriStar II PLUS porosimeter. To perform the $\mathrm{N}_{2}$ adsorption measurements, the samples were previously degassed under vacuum for 24 hours, at $90{ }^{\circ} \mathrm{C}$. Surface area was determined using the Brunauer-Emmett-Teller (BET) method. ${ }^{[46]}$ Pore size distribution between 0.5 and $40 \mathrm{~nm}$ was determined from the adsorption branch of the isotherm by means of the Barret-Joyner-Halenda $(\mathrm{BJH})$ method. ${ }^{[47]}$ For cell proliferation test, cell viability measurements were taken in a Wallac 1420 workstation. Thermogravimetric analysis were carried out on a TGA/SDTA 851e Mettler Toledo balance, using an oxidant atmosphere (air, $80 \mathrm{~mL} / \mathrm{min}$ ) with a heating program consisting on a heating ramp of $10{ }^{\circ} \mathrm{C}$ per minute from 393 to $1273 \mathrm{~K}$ and an isothermal heating step at this temperature during 30 minutes.

\section{Synthesis of materials}

Synthesis of mesoporous bioactive glass (S1). $80 \% \mathrm{SiO}_{2}-15 \% \mathrm{CaO}$ $5 \% \mathrm{P}_{2} \mathrm{O}_{5}(\% \mathrm{~mol})$ mesoporous glass (S1) was synthetized by evaporation induced self-assembly (EISA) method, using P123 triblock copolymer as structure directing agent. TEOS, TEP and calcium nitrate $\mathrm{Ca}\left(\mathrm{NO}_{3}\right)_{2} \cdot 4 \mathrm{H}_{2} \mathrm{O}$ were used as $\mathrm{SiO}_{2}, \mathrm{P}_{2} \mathrm{O}_{5}$ and $\mathrm{CaO}$ sources respectively. In a typical synthesis, $4 \mathrm{~g}$ of $\mathrm{P} 123$ were dissolved in $60 \mathrm{~g}$ of ethanol with $1 \mathrm{~mL}$ of $\mathrm{HCl} 0.5 \mathrm{M}$ solution at room temperature. Afterwards, $7.18 \mathrm{~mL}$ of TEOS, $0.73 \mathrm{~mL}$ of TEP and $1.29 \mathrm{~g}$ of $\mathrm{Ca}\left(\mathrm{NO}_{3}\right)_{2} \cdot 4 \mathrm{H}_{2} \mathrm{O}$ were added under stirring in 3 hours intervals. The resulting solution was stirred for 12 hours and casted into Petri dishes (9 $\mathrm{cm}$ in diameter). The colourless solution was evaporated at $37^{\circ} \mathrm{C}$ for 1 day. Eventually, the dried gels were removed as homogeneous and transparent membranes and heated at $700{ }^{\circ} \mathrm{C}$ for 3 hours under air atmosphere. Finally, the MBG powder was gently milled and sieved, collecting the particle size fraction below $20 \mu \mathrm{m}$.

Synthesis of S2. $500 \mathrm{mg}$ of S1 were suspended in a solution of $145 \mathrm{mg}$ of levofloxacin in $20 \mathrm{~mL}$ of anhydrous acetonitrile under inert atmosphere. After stirring for 24 hours in order to achieve the maximum pore loading, $0.5 \mathrm{~mL}$ of 3-[2-(2 aminoethylamino)ethylamino] propyltrimethoxysilane (N3) was added, and the mixture was stirred for 5.5 hours. Finally, the solid was filtered and dried under vacuum. Following this procedure, the levofloxacin spectrum does not change before and after loading into the mesoporous bioglass.

Synthesis of S3. $400 \mathrm{mg}$ of solid S2 were suspended in a solution containing EDC 0.6 M, ATP $0.5 \mathrm{M}$ and an excess of levofloxacin. The $\mathrm{pH}$ of the solution was previously adjusted to 7.6 with $\mathrm{NaOH}$. The suspension was stirred for 6 hours at room temperature. The resulting solid was filtered and dried under vacuum.

\section{Stimuli-responsive studies with $\mathbf{S 3}$}

$4 \mathrm{mg}$ of $\mathrm{S} 3$ were suspended in $10 \mathrm{~mL}$ of water at $\mathrm{pH} 7.6$ adjusted with $\mathrm{NaOH}$. The suspension was divided in two, and acid phosphatase (2.5 $\mathrm{mg}, 1.25$ enzymatic units) was added to one of the samples. Both samples were stirred at $400 \mathrm{rpm}$ and $37{ }^{\circ} \mathrm{C}$, and then several $250 \mu \mathrm{L}$ aliquots were taken for each sample at different times $(0,1,2,4,7$ and 24 hours). These aliquots were filtered with PTFE filters $(0.22 \mu \mathrm{m})$ to monitor the levofloxacin release by fluorescence spectroscopy ( $\lambda_{\text {ex }} 292$ $\mathrm{nm}, \lambda_{\mathrm{em}} 494 \mathrm{~nm}$ ). Moreover, the same experiment was performed in the presence of other enzymes as amylase and lipase, and in the presence of denatured APase. For this, $10 \mathrm{mg}$ of $\mathbf{S} 3$ were suspended in $25 \mathrm{~mL}$ of water at $\mathrm{pH} 7.6$ and the suspension was divided in five samples. APase, denatured APase, lipase and amylase (7.5 enzymatic units) were added to respective samples. The samples were stirred at $400 \mathrm{rpm}$ and $37^{\circ} \mathrm{C}$ and then $250 \mu \mathrm{L}$ aliquots were taken for each sample at different times. These aliquots were filtered with PTFE filters $(0.22 \mu \mathrm{m})$ to monitor the levofloxacin release by fluorescence spectroscopy ( $\lambda_{\mathrm{ex}} 292 \mathrm{~nm}, \lambda_{\mathrm{em}} 494$ $\mathrm{nm})$.

\section{Bioactivity assays with $\mathrm{S} 1$ and $\mathrm{S3}$.}

In vitro bioactivity assays were carried out on $\mathbf{S 1}$ and $\mathbf{S} 3$ solids. $10 \mathrm{mg}$ of each solid were soaked into $2 \mathrm{~mL}$ of filtered simulated body fluid (SBF) ${ }^{35}$ at $37{ }^{\circ} \mathrm{C}$ under sterile conditions. The evolution of the solids surfaces were analysed by Fourier transform infrared (FTIR) spectroscopy and field emission scanning electron microscopy (FESEM).

\section{Bacterial viability assay}

E. coli DH5a culture conditions. For bacterial viability studies, Escherichia coli (E.coli) DH5a cell culture was used. Bacteria cells were maintained in glycerol $15 \%$ at $-80^{\circ} \mathrm{C}$. For the assays, cells were grown for 24 hours at $37{ }^{\circ} \mathrm{C}$ and under constant stirring with $5 \mathrm{~mL}$ of LB medium. Cells from $1 \mathrm{~mL}$ of culture were collected by centrifugation for 30 seconds at $13000 \mathrm{rpm}$ and resuspended in $1 \mathrm{~mL}$ of milliQ water at $\mathrm{pH}$ 7.6 
Bacterial viability assay. In order to determine the antibacterial effect of S3, $5 \mathrm{mg}$ of the solid were stirred in water at $\mathrm{pH} 7.6$ in the absence and the presence of acid phosphatase for 24 hours. Then, two suspensions of $10^{4}$ cells $\cdot \mathrm{mL}^{-1}$ were prepared and treated with $50 \mu \mathrm{L}$ of each sample. A control experiment with no solid was also carried out. The suspensions were stirred at $180 \mathrm{rpm}\left(37^{\circ} \mathrm{C}\right)$ during 10 minutes. Then, they were suitably diluted with milliQ water $(\mathrm{pH} 7.6)$ in order to obtain a cell growth easy to quantify. Finally, $100 \mu \mathrm{L}$ of the new dilutions were seeded in LB plates ( $3 \%$ agar) and incubated at $37{ }^{\circ} \mathrm{C}$ for 24 hours. Then, Colony Formation Units (CFU) were quantified.

\section{Citotoxicity assay}

\section{Cell culture conditions}

U-2-OS human osteosarcoma cells were purchased from ATCC and were grown in DMEM supplemented with $10 \%$ of FBS. Cells were incubated at $37{ }^{\circ} \mathrm{C}$ in an atmosphere of $5 \%$ carbon dioxide and $95 \%$ air and underwent passage twice a week.

Cell toxicity assay. In order to study viability of cells in contact with S3, $\mathrm{U}$-2-OS cells were seeded in a 96-well plate in a density of 10.000 cells.well ${ }^{-1}$ and treated with $25,50,100$ and $200 \mu \mathrm{g} \cdot \mathrm{mL}^{-1}$ of S3 in PBS. A control assay with no solid was also carried out. After 24 and 48 hours of incubation, WST-1 was added in order to determine cell viability. Cells were incubated for 60 minutes, and then absorbance was measured at $595 \mathrm{~nm}$.

\section{Statistics}

Statistics Data are expressed as means-standard deviations of experiments. Statistical analysis was performed using the Statistical Package for the Social Sciences (SPSS) version 22 software (IBM). Statistical comparisons were made by analysis of variance (ANOVA). In all of the statistical evaluations, $\mathrm{P}<0.01$ was considered as statistically significant.

\section{Acknowledgements}

The authors thank the Spanish Government for projects MAT2015-64139-C04-01-R, MAT2015-64831-R, MAT2016-75611-R (AEI/FEDER, UE). Also, Generalitat Valenciana (project PROMETEOII/2014/047) and CIBERBBN (project SPRING) are acknowledged for their support. M.V.-R. acknowledges funding from the European Research Council (Advanced Grant VERDI; ERC-2015AdG Proposal 694160). L.P. thanks Universitat Politècnica de València for her FPI grant. N. G. C. and A. G thank to Ministerio de Ciencia e Innovación and Ministerio de Educación, Cultura y Deporte for their predoctoral fellowships. The authors also thank the Electron Microscopy Service at the UPV for their support.

Keywords: nanomaterials, controlled release, mesoporous bioactive glasses.

[1] R. Bernabei, A. M. Martone, E. Ortolani, F. Landi, E. Marzetti, Clin. Cases Miner. Bone Metab. 2014, 11, 201-7.

[2] J. Li, H. L. Wang, Implant Dent. 2008, 17, 389-401.
[3] A. S. Herford, J. S. Dean, Oral Maxillofac. Surg. Clin. North Am. 2011, 23, 433-442.

[4] C. R. Arciola, L. Visai, F. Testoni, S. Arciola, D. Campoccia, P. Speziale, L. Montanaro, Int. J. Artif. Organs 2011, 34, 771-780.

[5] J. A. Inzana, E. M. Schwarz, S. L. Kates, H. A. Awad, Bone 2015, 72, 128-136.

[6] L.-C. Gerhardt, A. R. Boccaccini, Materials (Basel). 2010, 3, 38673910 .

[7] F. Baino, G. Novajra, C. Vitale-Brovarone, Front. Bioeng. Biotechnol. 2015, 3, 202

[8] L. L. Hench, Science (80-. ). 1980, 208, 826-831.

[9] C. Argyo, V. Weiss, C. Bräuchle, T. Bein, Chem. Mater. 2014, 26 , 435-451.

[10] X. X. Yan, H. X. Deng, X. H. Huang, G. Q. Lu, S. Z. Qiao, D. Y. Zhao, C. Z. Yu, J. Non. Cryst. Solids 2005, 351, 3209-3217.

[11] X. Yan, C. Yu, X. Zhou, J. Tang, D. Zhao, Angew. Chemie - Int. Ed. 2004, 43, 5980-5984.

[12] N. Gómez-Cerezo, I. Izquierdo-Barba, D. Arcos, M. Vallet-Regí, J. Mater. Chem. B 2015, 3810-3819.

[13] L. L. Hench, R. J. Splinter, W. C. Allen, T. K. Greenlee, J. Biomed. Mater. Res. 1971, 5, 117-141.

[14] J. R. Jones, J. Eur. Ceram. Soc. 2009, 29, 1275-1281.

[15] M. Manzano, M. Vallet-Regí, J. Mater. Chem. 2010, 20, 5593-5604.

[16] M. Vallet-Regí, D. Arcos, Acta Mater. 2013, 61, 890-911.

[17] Y. Zhu, S. Kaskel, Microporous Mesoporous Mater. 2009, 118, 176 182.

[18] D. Lembo, M. Donalisio, A. Civra, M. Argenziano, R. Cavalli, Exp. Opin. Drug Deliv. 2018, 15, 93-114.

[19] W. Chen, J. Ouyang, H. Liu, M. Chen, K. Zeng, J. Sheng, Z. Liu, Y. Han, L. Wang, J. Li, L. Deng, Y-N. Liu, S. Guo, Adv. Mater., 2017, 29, 1603864.

[20] B.L. Li, M. I. Setyawati, L. Chen, J. Xie, K. Ariga, C.-T. Lim, S. Garaj, D. T. Leong, ACS Appl. Mater. Interfaces, 2017, 9, 15286-15296.

[21] M. Komiyama, K. Yoshimoto, M. Sisido, K. Ariga, Bull. Chem. Soc. Jpn. 2017, 90, 967-1004.

[22] E. Aznar, M. Oroval, L. Pascual, J. R. Murguía, R. Martínez-Máñez, F. Sancenón, Chem. Rev. 2016, 116, 561-718.

[23] E. Aznar, C. Coll, M. Dolores Marcos, R. M. Artínez-M Áñez, F. Sancenón, J. Soto, P. Amorós, J. Cano, E. Ruiz, Chem. - A Eur. J. 2009, 15, 6877-6888.

[24] J. L. Vivero-Escoto, I. I. Slowing, C.-W. Wu, V. S.-Y. Lin, J. Am. Chem. Soc. 2009, 131, 3462-3463.

[25] J. T. Sun, Z. Q. Yu, C. Y. Hong, C. Y. Pan, Macromol. Rapid Commun. 2012, 33, 811-818.

[26] A. López-Noriega, E. Ruiz-Hernández, E. Quinlan, G. Storm, W. E. Hennink, F. J. O'Brien, J. Control. Release 2014, 187, 158-166.

[27] E. Bringas, Ö. Köysüren, D. V. Quach, M. Mahmoudi, E. Aznar, J. D. Roehling, M. D. Marcos, R. Martínez-Máñez, P. Stroeve, Chem. Commun. 2012, 48, 5647.

[28] H. J. Kim, H. Matsuda, H. Zhou, I. Honma, Adv. Mater. 2006, 18, 3083-3088.

[29] L. Tan, M. Y. Yang, H. X. Wu, Z. W. Tang, J. Y. Xiao, C. J. Liu, R. X. Zhuo, ACS Appl. Mater. Interfaces 2015, 7, 6310-6316.

[30] Z. Zhang, D. Balogh, F. Wang, R. Tel-Vered, N. Levy, S. Y. Sung, R. Nechushtai, I. Willner, J. Mater. Chem. B 2013, 1, 3159-3166.

[31] C. De La Torre, I. Casanova, G. Acosta, C. Coll, M. J. Moreno, F. Albericio, E. Aznar, R. Mangues, M. Royo, F. Sancenón, et al., Adv. Funct. Mater. 2015, 25, 687-695.

[28] I. Candel, E. Aznar, L. Mondragón, C. de la Torre, R. MartínezMáñez, F. Sancenón, M. D. Marcos, P. Amorós, C. Guillem, E. Pérez-Payá, et al., Nanoscale 2012, 4, 7237.

[32] A. Agostini, L. Mondragón, A. Bernardos, R. Martínez-Máñez, M. Dolores Marcos, F. Sancenón, J. Soto, A. Costero, C. ManguanGarcía, R. Perona, et al., Angew. Chemie - Int. Ed. 2012, 51, 10556-10560.

[33] M. Oroval, E. Climent, C. Coll, R. Eritja, A. Aviñó, M. D. Marcos, F. Sancenón, R. Martínez-Máñez, P. Amorós, Chem. Commun. 2013, 


\section{9, 5480 .}

[34] S. Alberti, G. J. A. A. Soler-Illia, O. Azzaroni, Chem. Commun. 2015, 51, 6050-6075

[35] L. Polo, N. Gómez-Cerezo, E. Aznar, J.-L. Vivancos, F. Sancenón, D. Arcos, M. Vallet-Regí, R. Martínez-Máñez, Acta Biomater. 2017, 50, 114-126.

[36] H. Bull, P. G. Murray, D. Thomas, A. M. Fraser, P. N. Nelson, Mol. Pathol. 2002, 55, 65-72.

[37] N. Mas, D. Arcos , L. Polo, E. Aznar, S. Sánchez-Salcedo, F. Sancenón, A. García, M.D. Marcos, A. Baeza, M. Vallet-Regí, R. Martínez-Máñez, Small, 2014, 10, 4859-4864.

[38] C. P. Price, A. Kirwan, C. Vader, Calcif. Tissue Int. 1982, 34, 285290

[39] L. J. Raggatt, N. C. Partridge, J. Biol. Chem. 2010, 285, 25103-8.

[40] J. A. Wright, S. P. Nair, Int. J. Med. Microbiol. 2010, 300, 193-204.

[41] L. L. Hench, J. Am. Ceram. Soc. 1991, 74, 1487-1510.

[42] T. Higuchi, J. Pharm. Sci. 1961, 50, 874-875.

[43] T. Higuchi, J. Pharm. Sci. 1963, 52, 1145-1149.

[44] E. Aznar, F. Sancenón, M.D. Marcos, R. Martínez-Máñez, P. Stroeve, J. Cano, P. Amorós, Langmuir 2012, 28, 2986-2996.

[45] R. Mathew, C. Turdean-Ionescu, B. Stevensson, I. Izquierdo-Barba, A. García, D. Arcos, M. Vallet-Regí, M. Edén, Chem. Mater. 2013, 25, 1877-1885.

[46] S. Brunauer, P. H. Emmett, E. Teller, J. Am. Chem. Soc. 1938, 60, 309-319.

[47] E. P. Barrett, L. G. Joyner, P. P. Halenda, J. Am. Chem. Soc. 1951 $73,373-380$ 
